\title{
BUDAYA KOSMOPOLITANISME DALAM PRAKTIK JUAL BELI DI PASAR TERAPUNG PADA KALIMANTAN SELATAN
}

\author{
Ariyadi \\ Dosen Universitas Muhammadiyah Palangkaraya \\ ariyadialbanjari@gmail.com
}

\begin{abstract}
This study aims to find out the transactions process in the floating market in South Kalimantan, the contract transactions used in it, and the value of cosmopolitanism in it's practice. This study is a descriptive field research, where the data collected is analyzed qualitatively. To obtain the required data, the author conducts observation, documentation and interviews directly with some of the floating market traders in South Kalimantan. The results of the study show that: First, there are two ways of buying and selling transactions in the floating market, which is barter (goods with equivalent goods) or by means of exchange (money). Second, the contract used in the Floating Market of South Kalimantan does not conflict with the principles of Islamic law. Third, the values of cosmopolitanism found in transactions in Floating Market include strengthening tolerance and brotherhood, there is no deception between traders and buyers or traders with traders, and mutual sincere between buyers with traders or traders with traders during the sale and purchase.
\end{abstract}

Abstrak: Penelitian ini bertujuan untuk mengetahui bagaimana cara transaksi jual beli di pasar terapung di Kalimantan Selatan, bagaimana akad transaksi jual beli di pasar terapung di Kalimantan Selatan serta bagaimana nilai kosmopolitanisme dalam praktik jual beli di pasar terapung pada Kalimantan Selatan. Penelitian ini merupakan penelitian lapangan (field research), penelitian ini bersifat deskriptif, dimana datadata yang dikumpulkan dianalisis secara kualitatif. Untuk memperoleh data yang diperlukan. Penulis melakuan observasi, dokumentasi dan wawancara secara langsung kepada sebagian pedagang Pasar Terapung di Kalimantan Selatan. Hasil penelitian menunjukkan bahwa: Pertama, cara transaksi jual beli dipasar perapung di Kalimantan Selatan dapat melalui Barter (Barang dengan barang yang setara) atau dengan alat tukar (uang). Kedua, akad yang digunakan di Pasar Terapung Kalimantan Selatan tidak bertentangan prinsip-prinsip syariat Islam. Ketiga, nilai-nilai kosmopolitanisme yang terdapat dalam transaksi di Pasa Terapung diantaranya yaitu menguatkan toleransi dan persaudaraan, tidak terdapat penipuan diantara pedagang dengan pembeli atau pedangan dengan pedagang, dan suka sama suka antara pembeli dengan pedagang atau pedagang dengan pedagang selama berlangsungnya jual beli.

Kata Kunci: Culture; Cosmopolitanism; Buying and selling; Floating Market.

\section{Pendahuluan}

Penelitian ini berangkat dari aktifitas yang sering dilakukan oleh masyarakat banjar yang selalu diidentikan dengan Islam. Secara sosiologis, keidentikan masyarakat banjar dengan islam merujukkan kepada identitas sosial yang merefleksikan suatu dasar ikatan sosial yang sama. Secara historis, Islam dijadikan sebagai sebuah poros sistem perdagangan oleh masyarakat banjar. Pada umumnya manusia mempunyai banyak kebutuhan yang harus dipenuhi untuk kelangsungan hidupnya. Berbicara mengenai kebutuhan, Kebutuhan adalah syarat hidup dasar manusia. Orang membutuhkan udara, makan, tempat tinggal, pakaian untuk bertahan hidup. Kebutuhan-kebutuhan ini menjadi keinginan ketika diarahkan ke objek tertentu yang dapat memuaskan kebutuhan tersebut. ${ }^{1}$

Banyak kegiatan yang dapat dilakukan manusia untuk memenuhi kebutuhannya, salah

1 Philip Kotler dan Kevin Lane Keller, Manajemen Pemasaran (Jakarta: Erlangga, 2009), 12. satunya adalah dengan melakukan jual beli. Jual beli merupakan kegiatan tukar menukar barang atau sesuatu yang memberi manfaat bagi pelakunya. Dalam ajaran Islam jual beli merupakan bagian dari muamalah yang diatur sedemikian rupa, sehingga tidak bertentangan dengan $\mathrm{Al}$ Qur'an dan Sunah. ${ }^{2}$

Perkara Muamalah telah diatur tentang permasalahan, dzalim atau aniaya berbuat sesuatu tidak pada tempatnya, atau mengurangi hak yang seharusnya di berikan olehnya. Gharar secara istilah adalah jual beli atau akad yang mengandung suatu barang yang karena tidak adanya kejelasan suatu barang baik dari segi harga, sehingga merugikan orang lain. Dusta, mengada-ada sesuatu yang tidak ada secara sengaja dengan maksudmaksud tertentu.

\footnotetext{
2 Agus Salim, "Praktik Barter Antara Barang Bekas Dengan Mainan Di Kecamatan Ketapang Kabupaten Sampit” (IAIN Antasari, 2010), http://idr.uinantasari.ac.id/2370/.
} 
Sifat curang diatas memperlakukan orang lain tidak seperti dirinya sendiri bahkan rasullulah telah mempertegaskan bagaimana sifat seorang muslim kepada muslim lainnya. "Tiada beriman seorang dari kamu sehingga dia mencintai segala sesuatu bagi saudaranya sebagaimana yang dia cintai bagi dirinya.” Serta, “...tidaklah (sempurna) berimannya seseorang sampai ia mencintai untuk saudaranya sesuatu yang ia cintai untuk dirinya sendiri berupa kebaikan" dan "...hendaknya ia perlakukan manusia sebagaimana ia suka diperlakukan demikian". 3

Proses pemenuhan kebutuhan hidup manusia dimulai dari melakukan pertukaran barang-barang antara satu dan lainya yang saling membutuhkan (double coincidence), sistem ini dikenal dengan perekonomian barter. Salah satu bentuk pertukaran barang ialah pasar, dan pasar terapung salah satunya, pasar terapung ialah pasar yang berada di atas perairan dan menggunakan jukung sebagai transportasi perdagangan.

Pasar Terapung di Provinsi Kalimantan Selatan, terdapat di tiga lokasi yang berbeda, pertama yaitu di daerah Kuin Banjarmasin, kedua di Siring kota Banjarmasin, dan ketiga di Desa Lok Baintan, Kecamatan Sungai Tabuk, Kabupaten Banjar. Pasar Terapung ini menjual berbagai jenis barang seperti, bibit-bibit tanaman, hasil produksi pertanian/perkebunan, buah-buahan, sembako, wadai (kue) dll. Pasar Terapung ini berlangsung tidak terlalu lama, paling lama sekitar tiga hingga empat jam, yaitu sekitar pukul 06.00 wita hingga 09.00 Wita.

Penelitian budaya kosmopolitanisme dalam praktik jual beli di pasar terapung pada Kalimantan Selatan ini menjadi unik bagaimana pedagang di pasar terapung dalam menjajakan jualan mereka kepada pembeli dimana dalam bertransaksi nanti mereka akan dihadapkan dengan pembeli tidak hanya masyarakat setempat tapi juga mereka melayani pembeli dari luar pulau dan bahkan pembeli dari mancanegara, pertanyaan sederhananya apakah penjual menaikkan harga dari harga normal dengan beberapa alasan, misal: bukan masyarakat setempat, atau tidak mengetahui harga, bisa juga dengan alasan mencari keuntungan lebih karena yang membeli orang mancanegara.

\footnotetext{
3 Shalih bin 'Abdul 'Aziz bin Muhammad bin Ibrahim, Syarb Al Arba'in An Nawawiyyah (Darul 'Ashimah, 1433).
}

\section{Landasan Teori}

\section{A. Pengertian Jual Beli}

Jual beli secara bahasa berasal dari bahasa Arab yang berarti "mengambil", 4 atau menukarkan sesuatu dengan sesuatu. ${ }^{5}$ Wahbah az-Zuhaili meyebutkan:" "Jual beli adalah proses tukar-menukar barang dengan barang".7 Menurut Taqiyuddin: "Memberikan sesuatu dengan imbalan sesuatu". ${ }^{8}$ Muhammad Ismail al-Kahlany "Pemilikan suatu harta dengan harta yang lain". 9 Dan juga Jual beli adalah terjemahan dari kata Al-Bai'u. Al-Bai'u secara etimologi adalah mengambil dan memberikan sesuatu. Ia diambil dari kata $b a^{\prime} a$, di mana seseorang menjulurkan tangannya saat melakukan transaksi atau ketika mengambil yang ditransaksikan, baik uang atau barang. ${ }^{10}$

Adapun Dasar Pembahasan mengenai Hukum Jual Beli meliputi:

Surah Al-Baqarah ayat 275. 2) Surah AnNisa ayat 29. 3) Surah Al-Jumu'ah ayat 9. Umat Islam telah sepakat (ijma') atas kebolehan jual beli dan pelaksanaannya sudah berlaku (dibenarkan) sejak zaman Rasulullah saw hingga hari ini. ${ }^{11}$

Jual beli hukumnya boleh selama tidak dilaksanakan dengan cara melanggar aturan agama, sebagaimana yang terdapat dalam kaidah ushul fiqih yaitu:

"Asal akad dan muamalah adalah sah, sehingga ada dalil yang membatalkan dan mengharamkannya."12

Berdasarkan keterangan yang berasal dari beberapa dalil di atas, maka jelaslah bahwa jual

\footnotetext{
4 Ismail Nawawi dan Zaenudin A Naufal, Fikih Muamalah Klasike dan Kontemporer: Hukum Perjanjian, Ekonomi, Bisnis, dan Sosial (Jakarta: Ghalia Indonesia, 2012), 75

5 Sayyid Abu Bakar Muhammad Syatha ad-Dimyathi, I'anah Al-Thalibin (Beirut: Daar Al Fikr, 2005), 5.

${ }^{6}$ Wahbah Az-Zuhaili, Al-Fiqhu al-Islami wa Adillatubu, vol. 5 (Damaskus: Daar Al Fikr, 2006), 3304.

7 Wahbah Az-Zuhaili, Al-Fiqhu al-Islami wa 'adillatubu, trans. oleh Abdul Hayyie al-Kattani, vol. 5 (Jakarta: Gema Insani, 2011), 25.

8 Taqiyuddin Abi Bakar bin Muhammad al Husaini, Kifayatul Akbyar (Beirut: Dar al-Kitab al-Ilmiyah, t.t.), 326.

9 Muhammad bin Ismail al-Kahlany, Subulus Salam (Beirut: Dar al-Kitab al-Ilmiyah, t.t.), 3.

10 Abdullah bin Abdurrahman Al-Bassam, Taudhib Al Abkam min Bulugh Al Maram, trans. oleh Thahirin Saputra (Jakarta: Pustaka Azzam, 2006), 216.

${ }^{11}$ Sayyid Sabiq, Fiqih Sunnah, trans. oleh Kamaluddin A. Marzuki (Bandung: Al-Ma’arif, 1997), 48.

12 Abdul Hamid Hakim, Al-Bayan (Jakarta: Sa'adiyah Putra, t.t.), 208.
} 
beli itu hukumnya dibolehkan menurut Alquran dan Hadis serta Ijma' umat Islam selama jual beli itu dilaksanakan sesuai dengan rukun dan syaratnya tanpa ada unsur paksaan, kecurangan dan tipuan, didalamnya dan hendaknya dilakukakan dengan kejujuran dan keikhlasan sehingga tercipta rasa suka sama suka di antara kedua belah pihak.

\section{B. Rukun dan Syarat Jual Beli}

Transaksi jual beli ada beberapa unsur yang harus dipenuhi, sehingga transaksi jual beli dapat berjalan sesuai dengan ketentuan syara' maka dikenal istilah rukun dan syarat jual beli.

Rukun jual beli tersebut adalah sebagai berikut:

1. Akad (ijab kabul) ${ }^{13}$

2. Orang yang berakad

3. Barang yang menjadi objek transaksi.

Syarat jual beli tersebut adalah sebagai berikut:

1. Suci bukan benda benda najis seperti anjing dan yang lainnya.

2. Memberi manfaat menurut syara'

3. Jangan digantungkan, seperti jika ayahku pergi, ku jual motor ini kepadamu.

4. Tidak dibatasi waktunya.

5. Dapat diserahkan dengan cepat maupun lambat.

6. Milik sendiri.

7. Diketahui, baik banyaknya, takarannya, atau ukuran-ukuran yang lainnya, maka tidaklah sah jual beli yang menimbulkan keraguan salah satu pihak. ${ }^{14}$

Berdasarkan ketentuan Islam, setiap perbuatan haruslah memenuhi kedua unsur tersebut, yaitu rukun dan syarat-syaratnya.

\section{Kosmopolitanisme}

Kosmopolitanisme didefinisikan sebagai sebuah keyakinan bahwa mssyarakat di dunia sejatinya merupakan suatu kesatuan dalam sebuah tatanan politik-etis global berdasarkan asas kemanusiaan. ${ }^{15}$ Kosmopolitanisme merupakan harapan ideal tentang warga dunia tanpa perbatasan, dan kosmopolitanisme bersumber dari inspirasi pemikiran humanitas rasional, sebuah nilai yang terkandung dalam diri setiap manusia. Clash of civilization atau perbenturan budaya yang pernah dituliskan

13 Hendi Suhendi, Fiqh Muamalah (Jakarta: Raja Grafindo Persada, 2007), 70.

14 Sulaiman Rasjid, Fiqh Islam (Bandung: Sinar Baru, 1992), 266.

15 Gannaway dan Adam, "What is Cosmopolitanism?" (MPSA Conference Paper, 2009), 1-2. oleh Huntington menyebabkan manusia saling curiga-mencurigai. Menurut Fathullah Gülen, salah satu upaya menjawab Clash of civilization tersebut adalah dengan dialog. Dengan landasan saling mengakui dan menghargai, dialog dapat digunakan sebagai pijakan dalam menata dunia yang plural, membuka perspektif baru akan adanya penghargaan Islam terhadap nilai-nilai toleransi dengan rekonsiliasi pemikiran-pemikiran agama dengan aturan kehidupan modern. ${ }^{16}$

Immanuel Kant berpendapat bahwa kosmopolitanisme sebagai suatu teori atau konsep yang berasumsi bahwa manusia pada dasarnya merupakan peduduk dunia yang dapat membentuk lingkaran universal. Kant juga menambakan bahwasannya masyarakat kosmopolitan merupakan federasi dari negara, bukan dari warga dunia. Tujuan akhir dari sistem kosmopolitan adalah untuk menciptakan perdamaian abadi sehingga negara dapat lebih fokus dalam pemanfaatan waktu dan upaya mereka untuk memberikan pendidikan budaya dan moralitas bagi bangsanya daripada harus membuang-buang sumber daya mereka untuk kepentingan ekspansionis. ${ }^{17}$

Islam yang memandu umatnya untuk bersikap ramah, toleran, dan mengedepankan kepedulian terhadap orang tidak mampu (mustad'afin) menunjukkan bahwa agama yang dibawa Nabi Muhammad SAW ini memiliki watak kosmopolitan. Lebih dari itu, kehadiran Islam yang bisa bersanding menjaga kerukunan dan perdamaian dengan pemeluk agama lain, suku, golongan, dan bangsa yang berbeda semakin menampilkan karakter kosmopolitnya.

Islam dapatlah disebut sebagai agama yang memiliki sifat kosmopolitan. Sebagaimana yang firman Allah SWT pada Surat Al-Anbiya' ayat 107 :

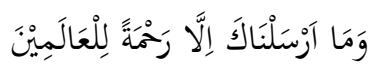

Artinya: "Dan kami tidak mengutusmu (Mubammad) melainkan (untuk menjadi) rahmat bagi selurub alam," (Q.S. Al-Anbiya: 107)

Agama yang saat ini dipeluk oleh sekitar 1,7 miliyar penduduk Bumi, menjadi ruh kehidupan bagi masyarakat global. Meski terkadang masih saja ada aksi-aksi biadab terorisme yang mengatas namakan Islam,

\footnotetext{
16 A. Rizqon Khamami, "Islam Kosmopolitan dalam Ajaran-Ajaran Fathullah Gülen," Jurnal Al-Fiker 15, no. 2 (2011): 157.

17 Pheng Cheah, "Cosmopolitanism," dalam Theory, Culture \&o Society, 2006, 486.
} 
namun hal itu tidak membuat umatnya berpindah pada keyakinan lain. Karena sesungguhnya tindakan brutal ekstrimis tidak ada dalam ajaran agama manapun, tak terkecuali Islam. Kosmopolitanisme tampak ke permukaan tatkala agama (Islam) menjadi alat dialog antar kebudayaan. Selain itu juga membuka ruang seluas-luasnya bagi bangsabangsa, suku-suku, dan peradaban lain untuk "beramah-tamah" sehingga, berbagai konflik yang selama ini muncul di berbagai negara (khususnya yang mengatasnamakan Islam) dapat dicegah.

Tempat dan Praktik Jual beli di pasar terapung di Kalimantan Selatan

A. Pasar Terapung Lok Baintan

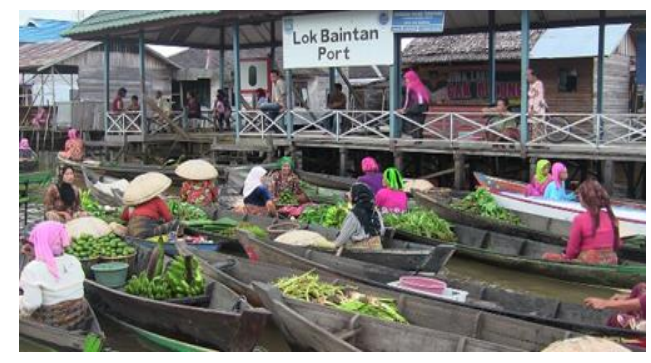

Pasar Terapung Lok Baintan adalah salah satu pasar tradisional yang berada di aliran sungai Martapura tepatnya di Desa Lok Baintan, Kecamatan Sungai Tabuk, Kabupaten Banjar. Kegiatan di Pasar Terapung ini berlangsung setiap hari dari pukul 06:00 sampai 09:00 wita Pedagang disini biasanya. menggunakan perahu untuk berjualan, Selain transaksi dilakukan di atas jukung (perahu), pedagang dan pembelinya juga tidak terpaku di suatu tempat, tetapi terus bergerak mengikuti arus sungai yang menjual beragam dagangan, seperti hasil produksi pertanian/perkebunan dan pedagangnyapun didominasi perempun.

Untuk menuju Pasar Terapung Lok Baintan bisa ditempuh dengan dua alternatif. Alternatif pertama, menyusuri sungai martapura dengan menggunakan Kelotok (kapal kayu/prahu motor), perjalanan dari Pusat Kota Banjarmasin dapat ditempuh sekitar 60 menit. Alternatif kedua, dengan menggunakan kendaraan darat seperti mobil.

\section{B. Pasar Terapung Muara Kuin}

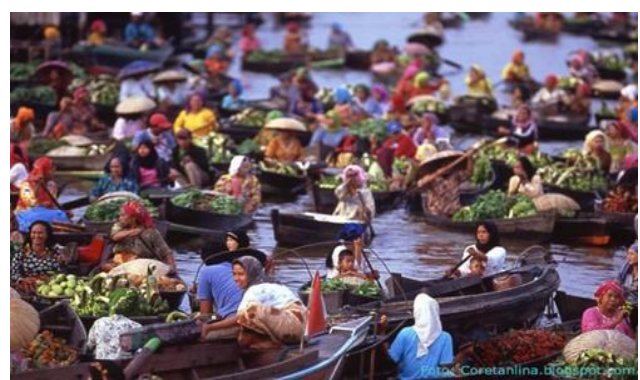

Pasar terapung ini sama seperti pasar terapung lok baintan, namun lokasinya yang berbeda yakni berada di atas sungai Barito di muara sungai kuin.

Alamat lengkap pasar terapung muara kuin yaitu di Jl. Kuin Utara, Kel. Kuin Selatan, Kec. Banjarmasin Barat, Kota Banjarmasin, Kalimantan Selatan. Untuk menuju ke Pasar Terapung Muara Kuin kita bisa langsung ke jalan Kuin Utara, lalu naik perahu kelotok atau perahu motor yang biasanya banyak terdapat di dermaga-dermaga di sepanjang sungai kuin. Salah satunya bisa melalui dermaga yang berada di dekat Masjid bersejarah Sulltan Suriansyah.

Sama dengan pasar terapung lokba intan, mulai operasi pasar terapung ini setelah sholat subuh, sekitar jam 05.00 Pagi sampai matahari terbit sekitar jam 08.00 wita.

\section{Pasar Terapung Siring Sungai Martapura}

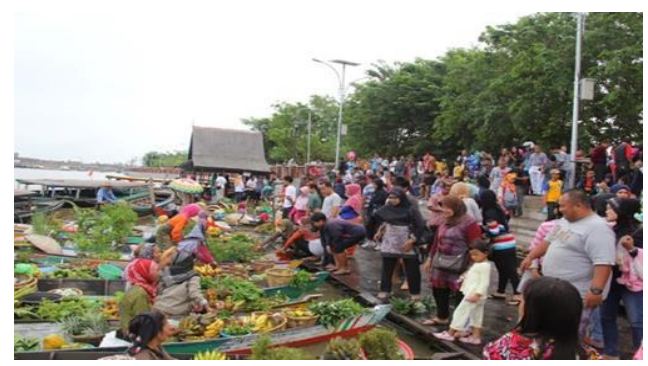

Beda dengan pasar terapung sebelumnya, pasar terapung di siring sungai martapura ini adalah program giat pasar Terapung oleh pemerintah kota Banjarmasin dalam rangka melestarikan Pasar Terapung.

Lokasi pasar terapung ini yaitu di Siring Sungai Martapura di Jl. Kapten Piere Tandean Kota Banjarmasin, Kalimantan Selatan. Namun tidak seperti pasar terapung yang lainnya yang buka setiap hari, pasar terapung di sini bukanya hanya setiap hari Minggu pagi dari Jam 07.00 sampai 12.00 wita. Dengan pelaksanaan Pasar Terapung di Siring sungai Martapura yang terletak di pusat kota diharapkan dapat lebih mendekatkan pasar terapung dengan 
masyarakat. Selain itu mungkin karena di sekitar pasar terapung ini juga terdapat objek wisata yang menarik lainnya, seperti Menara Pandang, Siring sungai martapura, dan patung bekantan menjadikan pasar ini semakin ramai.

Di Pasar Terapung ini para pedagang merapat di area pinggiran siring, dan pembeli di atas titian yang mengapung dengan alas bambu. Pasar terapung siring sungai martapura ini paling ramai di kunjungi di bandingkan Pasar Terapung Kuin dan Pasar Terapung Lok Baintan, mungkin karena mudahnya akses ke sini dan waktu yang lumayan panjang beroperasinya pasar tradisional ini, menjadikan Pasar Terapung Siring Sungai Martapura sebagai hiburan favorit masyarakat Banjarmasin untuk mengisi waktu liburan bersama keluarga atau teman-teman.

\section{Hasil Penelitian}

Untuk mengetehui budaya kosmopolitanisme pada pasar terapung di Kalimantan Selatan, seiring peneliti melakukan penelitian terhadap enam pedagang yang pada masing-masing pasar terapung hanya dua pedagang di tiap lokasi, dapat diketahui dari data yang peneliti kumpulkan dengan teknik wawancara dan observasi dengan uraian sebagai berikut:

a. MC ialah salah satu pedagang yang ada di pasar Terapung Lok Baintan, dia sudah lama berjualan di pasar tersebut sekitar 12 tahun, biasanya dia pergi berjualan sekitar jam 05:5006:00 pagi sampai jam 09:00 pagi. Dia menjual sayur-sayuran dan buah-buahan, Dari hasil wawancara yang saya lakukan dengan MC, MC mengatakan bahwa sebelum berangkat terlebih dulu dia melaksanakan sholat subuh, baru setelah itu dia berangkat ke Pasar Terapung Lok Baintan untuk menjajakan dagangannya, dalam menjajakan dagangannya dia juga mengatakan dalam berdagang dia tidak hanya melayani masyarakat lokal tapi juga sering mendapat pelanggan dari mancanegara.

MC melakukan praktik jual beli menggunakan uang sebagai alat tukar serta barter dikarenakan pada saat itu dia bertemu dengan pedagang lain yang sama-sama membutuhkan barang yang mereka inginkannya, pedagang yang menjadi rekan barternya, biasanya menawarkan terlebih dahulu untuk menukarkan ikan dengan sayur milik MC dengan nilai harga yang sama, biasanya ada pembeli dari luar negeri membeli barang jualannya dan dia mengaku menjual dengan harga yang sama dengan harga lokal dia tidak menambah harga dan mengurangi timbangan dan dia mengaku juga sering memberikan bonus berupa buah-buahan kepada pembeli mancanegara agar sering kesini lagi katanya. ${ }^{18}$

b. I ialah salah satu pedagang yang ada di pasar Terapung Lok Baintan, dia sudah lama berjualan dipasar tersebut sekitar 16 tahun, biasanya dia pergi berjualan sekitar jam 05:5006:00 pagi sampai jam 09:00 pagi. Dia menjual wadai (kue), Dari hasil wawancara dia mengaku, bahwa sebelum berangkat terlebih dulu dia melaksanakan sholat subuh, baru setelah itu dia berangkat ke Pasar Terapung Lok Baintan untuk menjajakan dagangannya, dalam menjajakan dagangan dia juga mengatakan dalam berdagang dia tidak hanya melayani masyarakat lokal, ada juga dari luar pulau serta juga sering mendapat pelanggan dari luar negeri .

I melakukan praktik jual beli menggunakan uang sebagai alat tukar tapi sesekali dia juga melakukan barter dikarenakan pada saat itu dia bertemu dengan pedagang lain yang samasama membutuhkan barang yang mereka inginkannya, dengan nilai harga yang sama, biasanya ada pembeli dari luar negeri membeli wadai (kue) dan dia mengaku menjual dengan harga yang normal, agar pembeli puas dan kada jara (jangan jera) datang ke sini. ${ }^{19}$

c. S seorang pedagang yang ada dipasar Terapung Muara Kuin, biasanya dia menjual buah-buahan seperti, buah pisang, jambu, jeruk, rambutan, manga, semangka dll. Barang yang dia jual pun merupakan hasil kebun sendiri dan sebagian ada juga yang dibelinya dari orang lain dan titipan tetangga (manjualakan). setiap hari pukul 06:00 dia sudah berangkat ke pasar Terapung untuk berjualan dan pulang sekitar pukul 09:00 pagi. S sudah sangat lama berjualan dipasar terapung ini, sejak umur 21 tahun.

$\mathrm{S}$ melakukan praktik jual beli menggunakan uang sebagai alat tukar tapi sesekali dia juga melakukan barter dikarenakan pada saat itu dia bertemu dengan pedagang lain yang samasama membutuhkan barang yang mereka inginkannya, dengan nilai harga yang sama, biasanya ada pembeli dari luar negeri membeli buah-buahan dan dia mengaku menjual dengan harga yang normal (sama dengan harga lokal),

18 Wawancara dengan MC di Pasar Terapung Lok Baintan, 21 Oktober 2017.

19 Wawancara dengan I di Pasar Lok Baintan, 21 Oktober 2017. 
agar pembeli puas dan merasa kada dipintari (ditipu) katanya dan datang ke sini. ${ }^{20}$

d. $\mathrm{R}$ adalah penjual buah dan sayur yang ada di pasar Terapung Muara Kuin, sewaktu kecil R sudah mulai ikut berjualan di pasar terapung ini bersama orang tuanya, sampai pada akhirnya $\mathrm{R}$ meneruskan pekerjaan orang tuanya sebagai pedagang di pasar terapung. Sama halnya seperti pedagang lainnya $\mathrm{R}$ berangkat berdagang subuh sekali dan jam 06:00 wita sudah di pasar dan pulang tidak menentu, paling lambat jam 09.00 pagi.

$\mathrm{R}$ melakukan praktik jual beli menggunakan uang sebagai alat tukar tapi sesekali dia juga melakukan barter dikarenakan pada saat itu dia bertemu dengan pedagang lain yang samasama membutuhkan barang yang mereka inginkannya, dengan nilai harga yang setara, biasanya ada pembeli dari luar negeri membeli buah-buahan dan dia mengaku menjual dengan harga yang normal (sama dengan harga lokal), karena sama saja katanya. ${ }^{21}$

e. NH seorang ibu pedagang yang ada di pasar Terapung Siring, biasanya dia menjual buahbuahan seperti, buah pisang, jambu, jeruk, rambutan, mangga dan semangka. Barang yang dia jual pun merupakan hasil kebun sendiri dan sebagian ada juga yang dibelinya dari orang lain. Dia berjualan hanya pada hari minggu saja pada jam 06:00 dia sudah berangkat .

NH biasanya bertransaksi barang dengan uang karena yang membeli dengan pedagang ialah masyarakat yang sambil berlibur di pinggir siring kota Banjarmasin masalah harga tidak ada perbedaan misalnya yang nukar (Membeli) itu masyarakat lokal atau pun masyarakat luar pulau yang kebetulan berlibur di Siring kita ini. ${ }^{22}$

f. H seorang ibu pedagang yang ada di pasar Terapung Siring, biasanya dia menjual wadai (kue) khas Banjar seperti, cucur, gaguduh, gumpal, buras, dll.23 Dia berjualan hanya pada hari minggu saja pukul 06:00 dia sudah berangkat .

$\mathrm{H}$ mengatakan uang sebagai alat tukar karena yang membeli masyarakat yang sedang berlibur bersama keluarga dan anak muda mudi yang singgah saat sedang berolah raga di pinggir siring kota Banjarmasin. masalah harga dan

\footnotetext{
20 Wawancara dengan S di Pasar Terapung Muara Kuin, 29 Oktober 2017.

21 Wawancara dengan R di Pasar Terapung Muara Kuin, 29 Oktober 2017.

22 Wawancara dengan $\mathrm{NH}$ di Pasar Terapung siring Kota Banjarmasin, 05 Oktober 2017

${ }^{23}$ Nama-nama kue khas di Kalimantan Selatan.
}

ukuran wadai (kue) tidak ada perbedaan misalnya yang nukar itu masyarakat lokal atau pun masyarakat luar pulau yang kebetulan berlibur di siring kita ini ${ }^{24}$

\section{Nilai-nilai Budaya Kosmopolitanisme dalam Praktik Jual Beli di Pasar Terapung}

Nilai-nilai budaya kosmopolitanisme dalam praktik jual beli di pasar terapung, setidaknya ada beberapa nilai yang dapat kita jadikan hikmah untuk kehidupan sehari-hari pada praktik jual beli masyarakat di pasar terapung di Kalimantan Selatan:

1. Kondisi suka sama suka antara pembeli dengan pedagang atau pedagang dengan pedagang itu diwujudkan di tempat berlangsungnya jual beli tersebut, dalam hal ini pandangan kosmopolitanisme hak seseorang sangat diihormati. Kemauan adalah hak pembeli, maka ia tidak boleh dipaksa membeli sesuatu.

2. Tidak terdapat penipuan diantara pedagang dengan pembeli atau pedangan dengan pedagang. Transaksi yang mengandung suatu hal yang tidak diketahui oleh salah satu pihak unknown to one party. Setiap transaksi dalam Islam harus didasarkan pada prinsip kerelaan antara kedua belah pihak (sama-sama ridha). Mereka harus complete information (mempunyai informasi yang sama) sehingga tidak ada pihak yang merasa ditipu atau dicurangi karena ada sesuatu yang keadaan di mana salah satu pihak tidak mengetahui informasi yang diketahui pihak lain, ini merupakan asymetric information. Unknown to one party dalam bahasa fikih disebut gharar, dan dapat terjadi dalam 4 (empat) hal, yakni dalam:

a. Kuantitas;

b. Kualitas;

c. Harga; dan

d. Waktu Penyerahan

3. Menguatkan toleransi dan persaudaraan

Pedagang dan penjual atau pedagang dengan pedagang tidak hanya mendapatkan untung tapi juga ada rasa persaudaraan, ada rasa toleransi, tolong menolong dalam kebaikan. Tidak hanya bagi warga lokal setempat bahkan dengan orang luar pulau serta mancanegara mereka tidak melakukan penipuan, menaikkan harga demi mendapatkan keuntungan sesaat, menonjolkan keunggulan barang tapi menyembunyikan cacatnya, melipat gandakan harga terhadap orang yang tidak mengetahui harga pasaran. Inilah nilai-nilai

${ }^{24}$ Wawancara dengan $\mathrm{H}$ di Pasar Terapung siring Kota Banjarmasin, 05 Oktober 2017. 
kosmopolitanisme yang terdapat dalam praktik di pasar terapung.

\section{Kesimpulan}

Berdasarkan uraian dan pembahasan tentang praktik jual beli pasar terapung di Kalimantan Selatan terhadap nilai-nilai kosmopolitanisme maka dapat ditarik kesimpulan sebagai berikut:

1. Cara bertransaksi jual beli dipasar perapung di Kalimantan Selatan berdapat beberapa cara

a. Barter,(Barang dengan barang yang setara)

b. Transaksi jual beli barang dengan alat tukar (uang).

2. Akad yang digunakan di pasar terapung Kalimantan Seletan secara global masih dalam ranah kebolehan baik ditijau dari syariat dan tidak bertentangan prinsip-prinsip syariat Islam.

3. Adapun nilai-nilai kosmopolitanisme diantaranya: Menguatkan toleransi dan persaudaraan, Tidak terdapat gharar diantara pedagang dengan pembeli atau pedangan dengan pedagang. Kondisi suka sama suka antara pembeli dengan pedagang atau pedagang dengan pedagang itu diwujudkan di tempat berlangsungnya jual beli tersebut.

\section{Daftar Pustaka}

A. Rizqon Khamami. "Islam Kosmopolitan dalam Ajaran-Ajaran Fathullah Gülen." Jurnal Al-Fikr 15, no. 2 (2011).

Abdul Hamid Hakim. Al-Bayan. Jakarta: Sa'adiyah Putra, t.t.

Abdullah bin Abdurrahman Al-Bassam. Taudhih Al Abkam min Bulugh Al Maram. Diterjemahkan oleh Thahirin Saputra. Jakarta: Pustaka Azzam, 2006.

Agus Salim. "Praktik Barter Antara Barang Bekas Dengan Mainan Di Kecamatan Ketapang
Kabupaten Sampit.” IAIN Antasari, 2010. http://idr.uin-antasari.ac.id/2370/.

Gannaway, dan Adam. "What is Cosmopolitanism?" MPSA Conference Paper, 2009.

Hendi Suhendi. Fiqh Muamalah. Jakarta: Raja Grafindo Persada, 2007.

Muhammad bin Ismail al-Kahlany. Subulus Salam. Beirut: Dar al-Kitab al-Ilmiyah, t.t.

Nawawi, Ismail, dan Zaenudin A Naufal. Fikih Muamalah Klasik dan Kontemporer: Hukum Perjanjian, Ekonomi, Bisnis, dan Sosial. Jakarta: Ghalia Indonesia, 2012.

Pheng Cheah. "Cosmopolitanism." Dalam Theory, Culture \& Society, 2006.

Philip Kotler, dan Kevin Lane Keller. Manajemen Pemasaran. Jakarta: Erlangga, 2009.

Sayyid Abu Bakar Muhammad Syatha adDimyathi. I'anah Al-Thalibin. Beirut: Daar Al Fikr, 2005.

Sayyid Sabiq. Fiqib Sunnah. Diterjemahkan oleh Kamaluddin A. Marzuki. Bandung: AlMa'arif, 1997.

Shalih bin 'Abdul 'Aziz bin Muhammad bin Ibrahim. Syarh Al Arba'in An Nawawiyyah. Darul 'Ashimah, 1433.

Sulaiman Rasjid. Fiqh Islam. Bandung: Sinar Baru, 1992.

Taqiyuddin Abi Bakar bin Muhammad al Husaini. Kifayatul Akhyar. Beirut: Dar al-Kitab alIlmiyah, t.t.

Wahbah Az-Zuhaili. Al-Fighu al-Islami wa Adillatubu. Vol. 5. Damaskus: Daar Al Fikr, 2006.

Al-Fiqhu al-Islami wa 'adillatubu. Diterjemahkan oleh Abdul Hayyie alKattani. Vol. 5. Jakarta: Gema Insani, 2011. 